\title{
PERFORMANCE EVALUATION OF PASSENGER CAR TIE ROD USING NUMERICAL AND THEORETICAL APPROACH WITH DIFFERENT MATERIALS
}

\author{
Pradeep Mahadevappa Chavan', M M M Patnaik ${ }^{2}$ \\ ${ }^{I}$ MTech Student, Dept. of Mechanical Engineering, KSIT Bangalore, Karnataka, India \\ ${ }^{2}$ Associate Professor, Dept. of Mechanical Engineering, KSIT Bangalore, Karnataka, India
}

\begin{abstract}
Tie rods or Track rods are an integral part of vehicle's steering system. Just as its name suggests a Tie rod ties vehicle's steering rack to the steering arm. Tie rod may get fail due to varying forces and bumping of vehicle during steering. The forces from the steering are also considered during the static condition of car. Vibration and buckling of Tie rod has been continuously a concern which may lead to structural failure if the resulting vibration and stresses are undesirable and excessive. So research work is aimed to assess buckling strength and compare buckling performance of Tie rod for different materials. Finite element models of the Tie rod also analyzed to obtain stiffness and stress distributions in each component. Based on the experimental test results, theoretical calculation results and finite element analysis with NASTRAN results, stiffness values are validated. The mode shape and natural frequency results for different materials obtained in the normal modal analysis are compared. In buckling analysis, the load factor obtained for different materials were compared and critical buckling load is calculated and is validated by theoretical calculations.
\end{abstract}

Keywords: Tie rod, Fluctuating forces, Stiffness, and Buckling etc...

\section{INTRODUCTION}

Form the several years a great deal of research work has been invested to find out the critical buckling loads of columns. Theoretical and experimental research has predicted that geometrical imperfections and modified boundary conditions greatly influence the critical buckling load magnitudes and scatter of columns. A Tie rod contains such geometrical imperfections and modified boundary conditions from a perfect cylindrical rod, since a Tie rod consists of outer and inner ends threaded into a middle rod body, with changing end conditions. So it is important to accurately find out the buckling loads of Tie rods, especially ones that are critical in compression used in automobile industries and aeronautical industry.

Depending upon the design criteria of minimizing compression margin safety coupled with the degree of difficulty to predict buckling characteristics and accurately calculating the critical buckling load is of high importance [1]. This research work gives an analytical study and that gives a designer a systematic approach to accurately predict the buckling load of a Tie rod. To accomplish the level of accuracy, a linear FE analysis is carried out. The goal of this work is to establish an acceptable method of predicting the stiffness, natural frequency and buckling load of a passenger car Tie rod due to axial compression.

\subsection{Parts Connected with Tie Rod}

Figure 1 gives the details of the parts that are connected to the Tie rod in the wheel steering mechanism. The important parts connected to Tie rod are

- Sway Bar

- Coil Spring

- Lower Control Arm

- Upper Control Arm

- Knuckle Arm

- Ball Joint

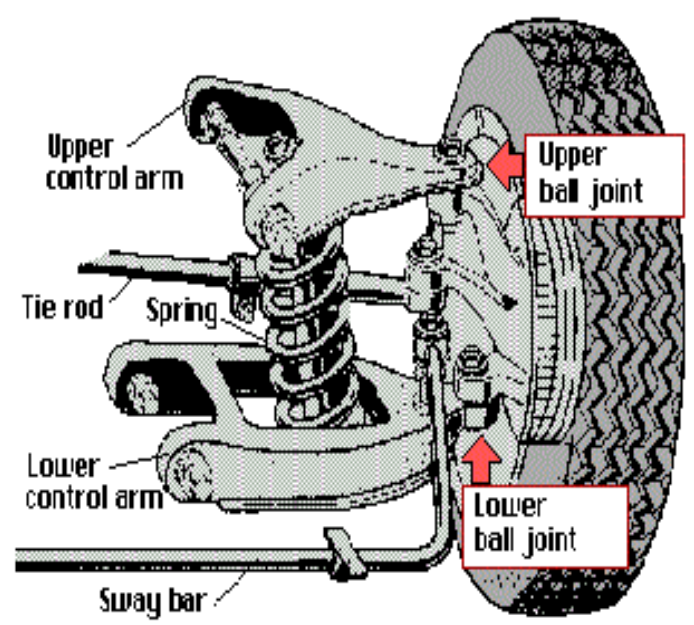

Fig -1: Connected Parts of Tie Rod 
The details of the above parts are given in the following sections

- Sway Bar

A Sway bar or stabilizer or anti roll bar is usually a torsion spring that resists body roll motions. Its purpose is to prevent the car's body from "rolling" in a sharp turn.

\section{- $\quad$ Coil Spring}

A coil is also called as helical spring is a mechanical device, which is typically used to store energy due to resilience and subsequently release it, to absorb shock, or to maintain a force between contacting surfaces.

\section{- Lower Control Arm}

The lower control arm hinged on bushes and bushes twist on the pin of lower control arm, which is bolted to the cross-member of the vehicle. The lower control arm functions to absorb the shock of the entire wheel.

\section{- Upper Control Arm}

It is part of the suspension system of the vehicle. They join suspension parts to the chassis and manage the motion of the wheels so that it synchronizes with that of the body of the light vehicle. It works with bushing that reduces friction and restrains the auto parts from going every which way.

\section{- Knuckle Arm}

Steering Knuckle arm is also known as hub carrier is one of automotive part on the vehicles and mostly been used in car suspension system.

\section{- Ball joint}

In an automobile industry ball joints are spherical bearings that connect the control arms to the steering knuckles. Motion control ball joints tend to be retained with an internal spring, which helps in preventing the vibration problems in the linkage.

\section{PROBLEM DEFINATION}

At first the theoretical study of Tie rod is done. The main work of Tie rod is to transmit the motion from steering arm to steering knuckle and sustain the forces and vibrations caused by bumps from tires due to uneven road surfaces. The main task in this study is to find the deformation and stresses induced in the Tie rod for various material combinations. The 3-D model is prepared for Tie-rod. Different types of materials are assigned and analysis is carried out using finite element analysis software named HyperMesh and MSC.NASTRAN. The results are compared with practical and theoretical results [2].

\subsection{Objectives of the Research Work}

The main Objectives of this research work are:

- Experimental analysis of the car Tie rod will be done.

- $\quad$ To generate 3D model of Tie rod initially accurate measurement of the Tie rod component will be done.

- Using that measured dimension, 3D modeling of the car Tie rod will be done using modeling software.

- To carry out all necessary checks on the model.

- Suitable boundary conditions are applied.

- Determination of displacement and stresses generated will be carried out through Static Analysis.

- Analytical approach for finding the stiffness and critical buckling load.

- Validation of results.

\subsection{Methodology}

In this work, finite element analyses were carried out to determine the characteristics of the Tie rod. All methodology principles and theories discussed were utilized to achieve the objectives. The combination of all the analysis results were used to develop virtual model created using FEM tools and the model was updated based on the correlation process. The research methodology flowchart for this project was shown in the below Figure 2 [2-3].

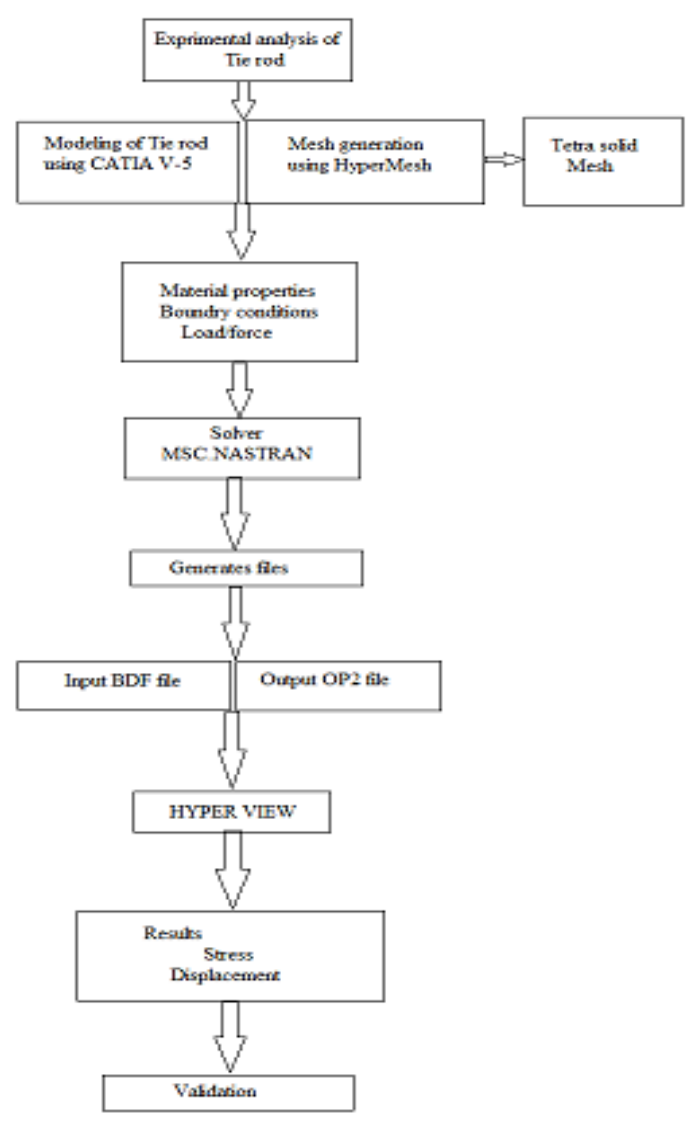

Fig -2: Flow Chart of Methodology Adopted in Research Work 


\section{GEOMETRICAL CONFIGURATION}

\subsection{CAD Model}

The CAD model of Maruthi Suzuki Baleno car Tie rod is taken for analysis. The model with the same dimension of the present Tie rod is considered for analysis [4].

\section{- 2-D Drafted CAD Model}

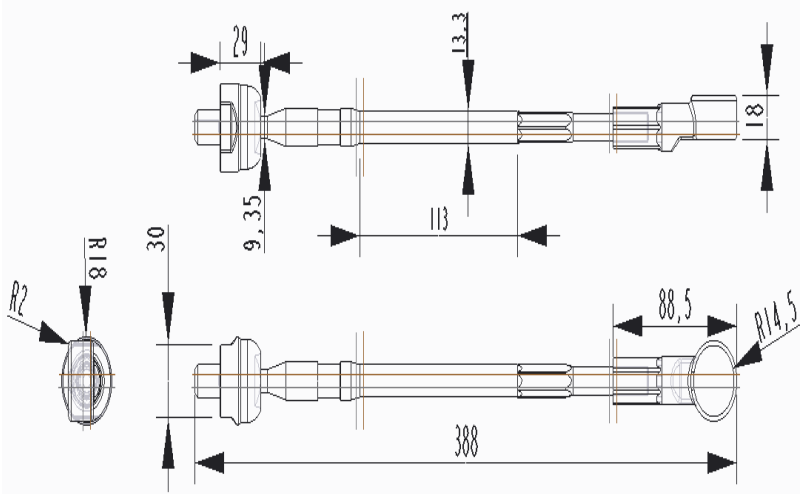

Fig -3: Schematic Front and Top View of 2D Drafted

\section{- 3D CatiaV-5 Model}

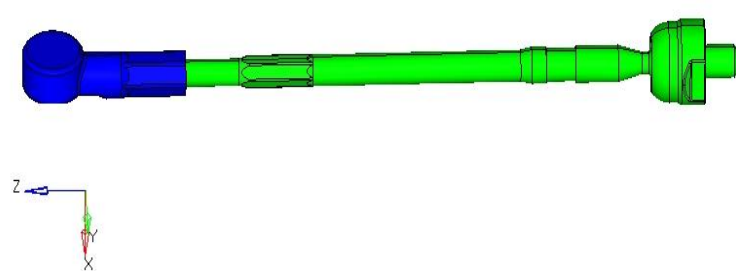

Fig -4: Representation of Tie rod in 3D view

\section{EXPERIMENTAL TEST DETAILS}

Two types of experimental test are to be carried out on the model Compression and Chemical composition test.

\subsection{Chemical Composition Test}

The chemical composition test is carried out in the Advanced Metallurgical Laboratory Bangalore. The material of the Tie rod is found to be carbon steel.

\subsection{Compression Test Results}

Table -1: Load and Displacement Results

\begin{tabular}{|l|l|l|}
\hline Sl. no. & $\begin{array}{l}\text { Applied load (P) } \\
\text { in Newton }\end{array}$ & $\begin{array}{l}\text { Recorded } \\
\text { change in } \\
\text { length (mm) }\end{array}$ \\
\hline 1 & 2000 & 0.0 \\
\hline 2 & 4000 & 0.025 \\
\hline 3 & 6000 & 0.04 \\
\hline 4 & 8000 & 0.065 \\
\hline 5 & 10,000 & 0.08 \\
\hline 6 & 12000 & 0.09 \\
\hline 7 & 14,000 & 0.1 \\
\hline 8 & 16,000 & 0.13 \\
\hline
\end{tabular}

\begin{tabular}{|l|l|l|}
\hline 9 & 18680 & 0.18 \\
\hline
\end{tabular}

\section{- Load Vs Displacement Graph}

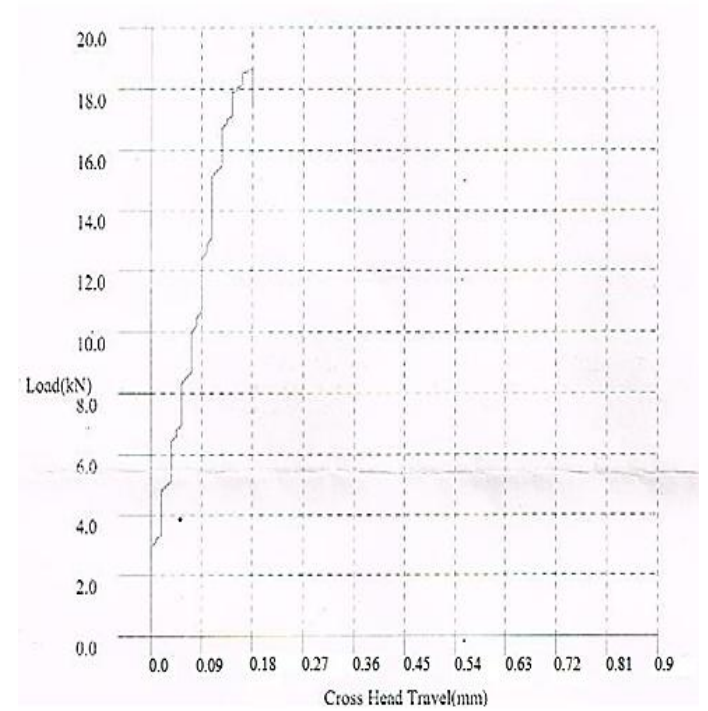

Fig -5: Load vs. Displacement Graph by Computerized UTM

The compression test is carried out to check the deflection of the Tie rod. The above figure 5 shows load vs. displacement graph. The load of $18.68 \mathrm{KN}$ is applied and $0.18 \mathrm{~mm}$ displacement is obtained. The load thus obtained ie. $18.68 \mathrm{KN}$ is taken for analysis in this project work.

\subsection{Stiffness Calculation for Tie Rod using Experimental Results}

Stiffness calculation for carbon steel Tie rod is carried out by taking $18.68 \mathrm{KN}$ load and deflection $0.18 \mathrm{~mm}$. Therefore, Stiffness $(\mathrm{K})$ is given by:

$$
K=\frac{\text { LOAD }}{\text { DEFLECTION }}
$$

The Stiffness obtained for carbon steel Tie rod experimentally is $103.77 \mathrm{KN} / \mathrm{mm}$.

\section{FINITE ELEMENT ANALYSIS}

\subsection{Meshing Details}

The meshing of Tie rod assembly is carried out in HyperMesh software. The finite element standard quality criteria considered in meshing of Tie rod component. Total number of elements and nodes used to create the FE model Tie rod assembly is 52527 elements and 12669 nodes. Total number of degrees of freedom in the car Tie rod assembly is 38007 [5]. 


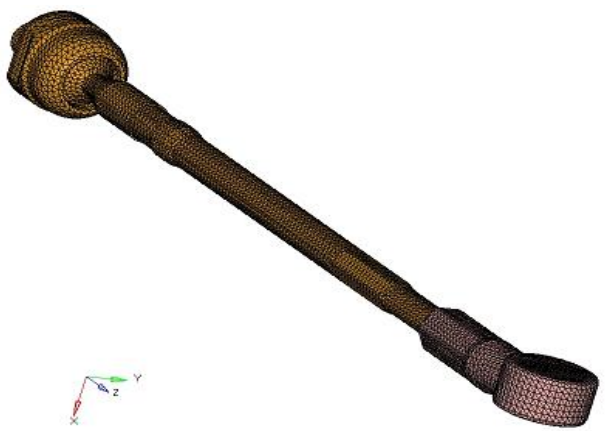

Fig -6: Meshed Tie Rod

Table -2: Meshing Details

\begin{tabular}{|l|l|l|l|}
\hline Sl. No. & $\begin{array}{l}\text { Type of } \\
\text { Element }\end{array}$ & $\begin{array}{l}\text { No. of } \\
\text { Element }\end{array}$ & $\begin{array}{l}\text { No. of } \\
\text { Nodes }\end{array}$ \\
\hline 1 & Tetrahedral & 52527 & 12669 \\
\hline
\end{tabular}

\subsection{Boundary Conditions}

The proper specification of boundary conditions is just as important for static analysis. The improper specification of the boundary conditions leads to incorrect answers. One such improper specification of boundary conditions is forgetting to fully constrain the structure. The boundary conditions applied is as shown in below figures.

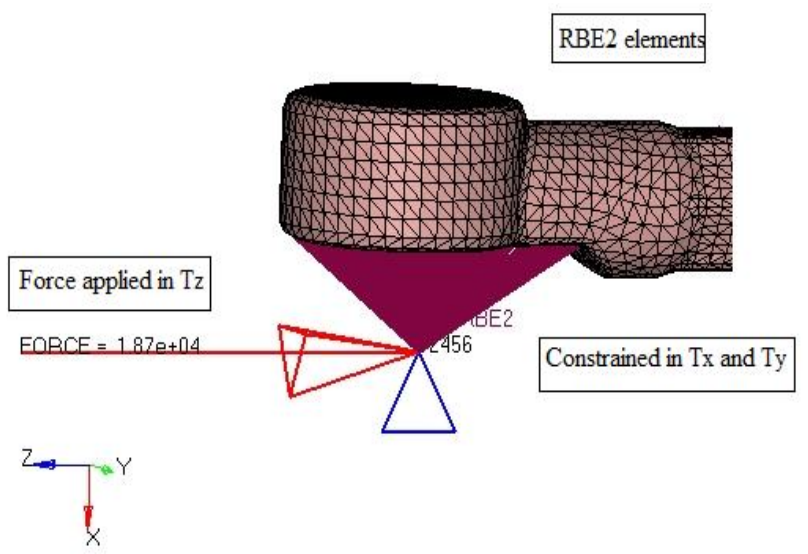

Fig -7: Tie Rod Boundary Conditions

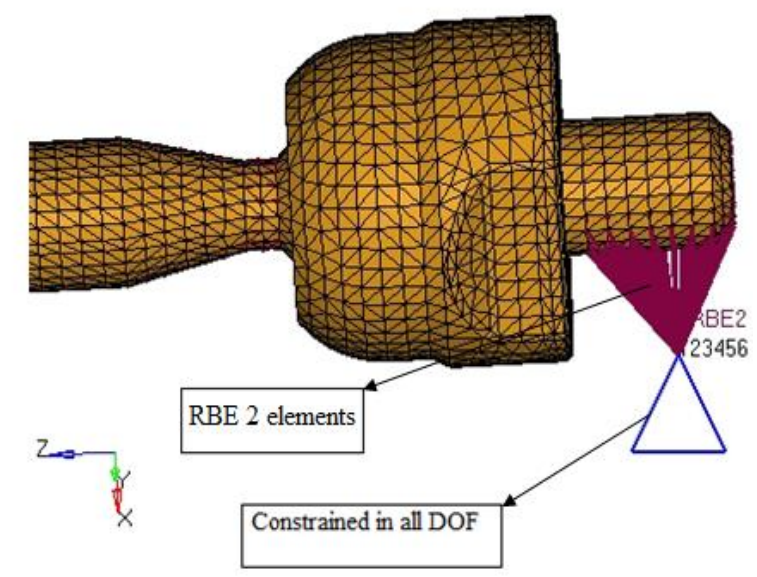

Fig -8: Tie Rod Boundary Conditions

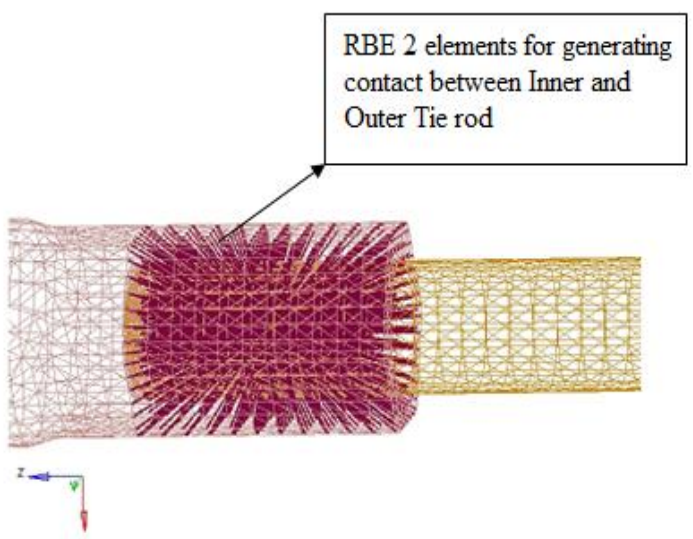

Fig -9: RBE2 Elements for Contact Generation

\subsection{Static FE Analysis of Tie Rod}

Static analysis is performed by applying $18.68 \mathrm{KN}$ force in $\mathrm{Tz}$ directions. And the boundary conditions are applied [6],

\section{- Displacement Results}

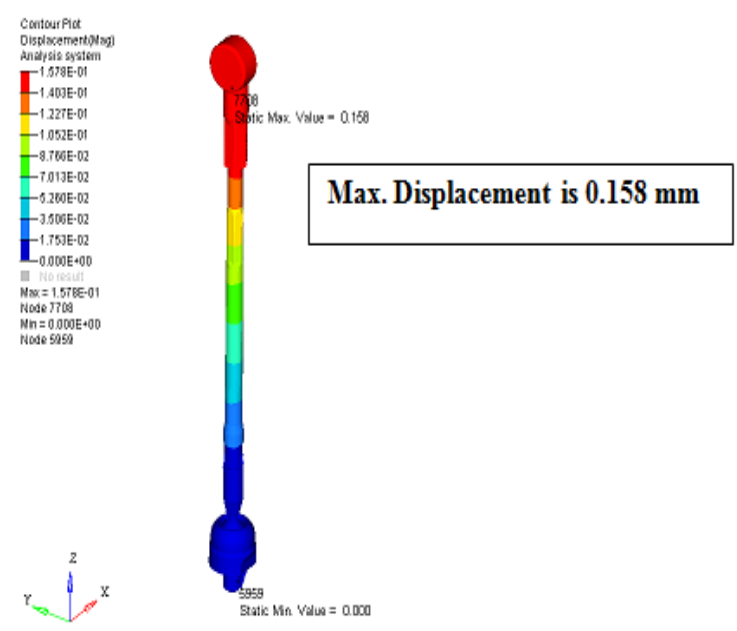

Fig -10: Displacement for Carbon Steel Tie Rod
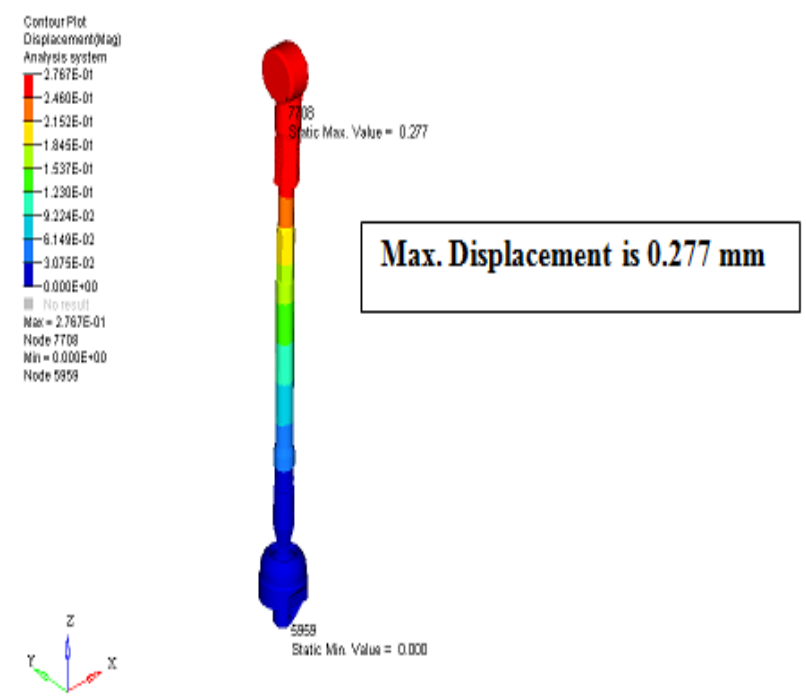

Fig -11: Displacement for Cast Iron Tie Rod 


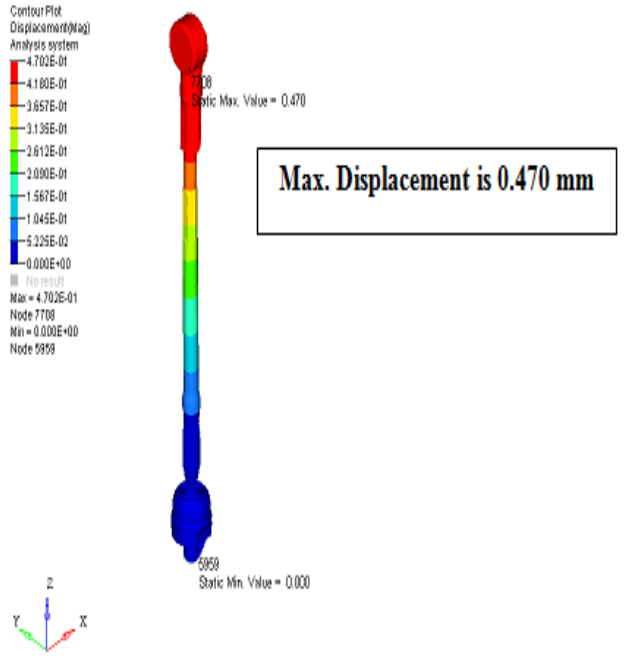

Fig -12: Displacement for Aluminium Alloy Tie Rod

\section{- $\quad$ Stress Results}

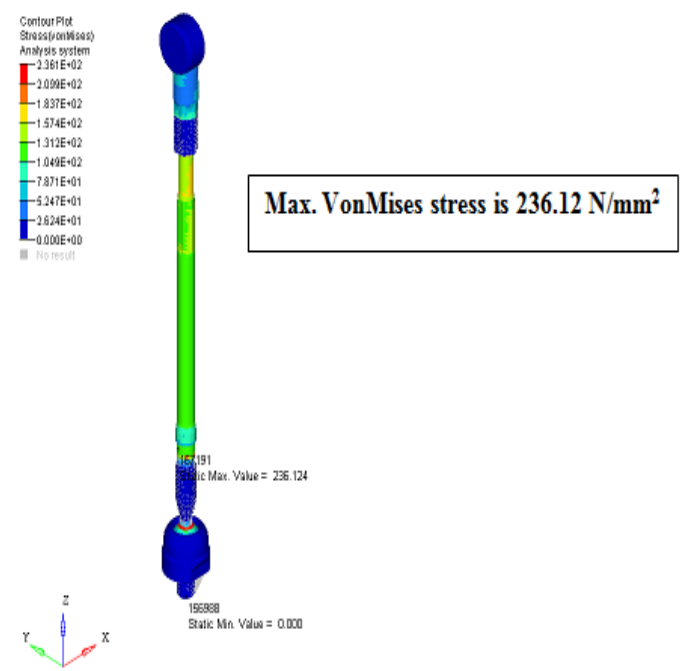

Fig -13: VonMises Stress for Carbon Steel Tie Rod

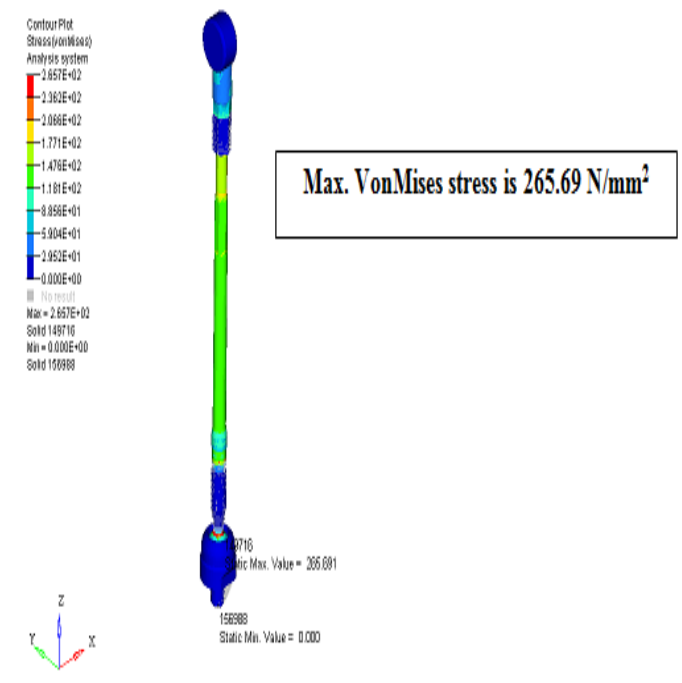

Fig -14: VonMises Stress for Cast Iron Tie Rod

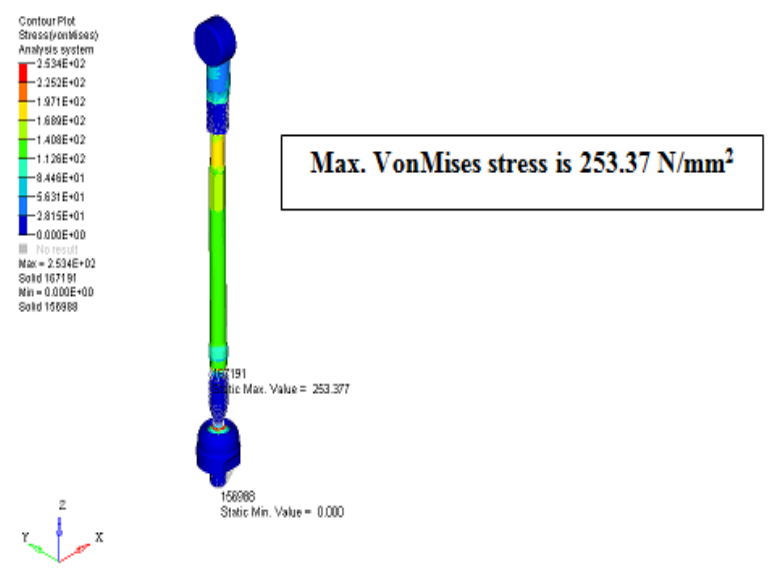

Fig -15: VonMises Stress for Aluminium Alloy Tie Rod

- Stiffness Calculation for Tie Rod using FE

\section{Results}

Stiffness calculation for Tie rod using FE results is carried out by taking $18.68 \mathrm{KN}$ load and $0.158 \mathrm{~mm}$ deflection for carbon steel Tie rod, $0.277 \mathrm{~mm}$ deflection for cast iron Tie rod and $0.470 \mathrm{~mm}$ deflection for aluminium alloy Tie rod.

Therefore, Stiffness $(\mathrm{K})$ is given by

$$
K=\frac{\text { LOAD }}{\text { DEFLECTION }}
$$

The Stiffness obtained for carbon steel Tie rod is $118.22 \mathrm{KN} / \mathrm{mm}$, cast iron Tie rod is $67.43 \mathrm{KN} / \mathrm{mm}$ and aluminium alloy Tie rod is $39.74 \mathrm{KN} / \mathrm{mm}$.

\subsection{Normal Modal FE Analysis for Tie rod}

The usually first step in performing a dynamic analysis is determining the natural frequencies and mode shapes of the car Tie rod with damping neglected. These results characterize the basic dynamic behavior of the car Tie rod and are an indication of how the structure will respond to dynamic loading [7-8].

- Natural Frequency and Mode Shape Results

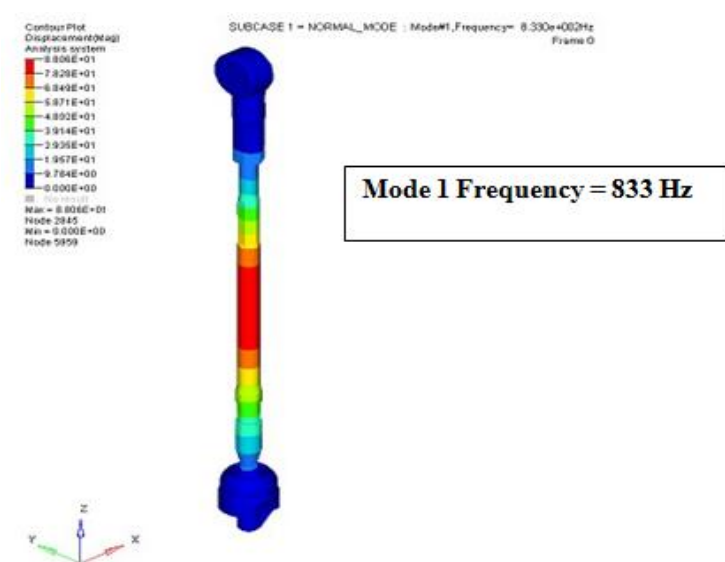

Fig -16: $1^{\text {st }}$ Mode Shape for Carbon steel Tie Rod 


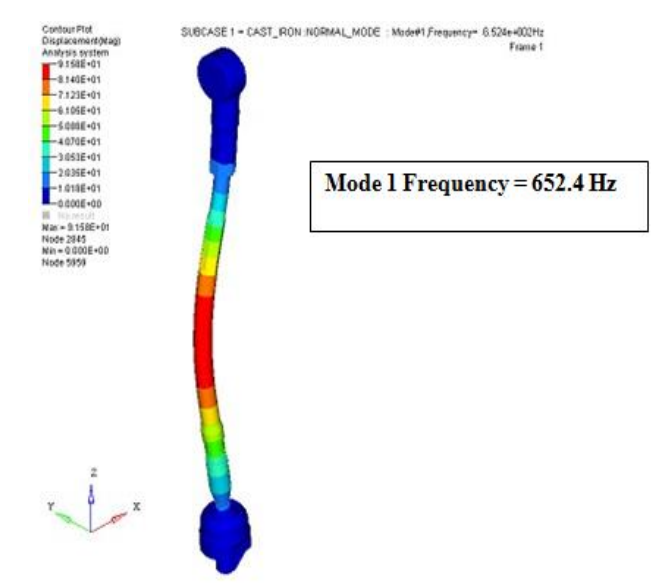

Fig -17: $1^{\text {st }}$ Mode Shape for Cast Iron Tie Rod

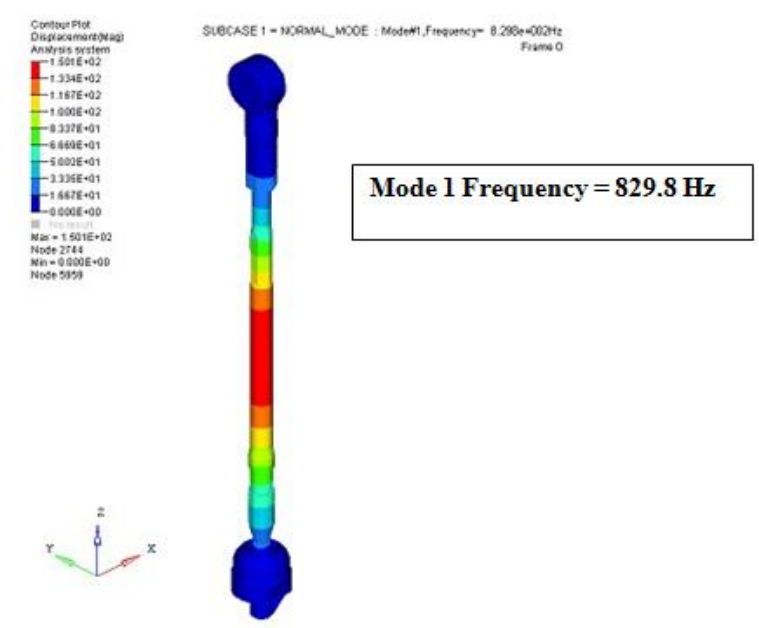

Fig -18: $1^{\text {st }}$ Mode Shape for Aluminium Alloy Tie Rod

\subsection{Buckling FE Analysis for Tie Rod}

Basically, buckling occurs in a rod due to instability. This means that a rod does not always buckle at the force that will correspond to the yield stress. Instead it will buckle at what is called the buckling force [9-10].

\section{- Buckling Analysis Results for Tie Rod}

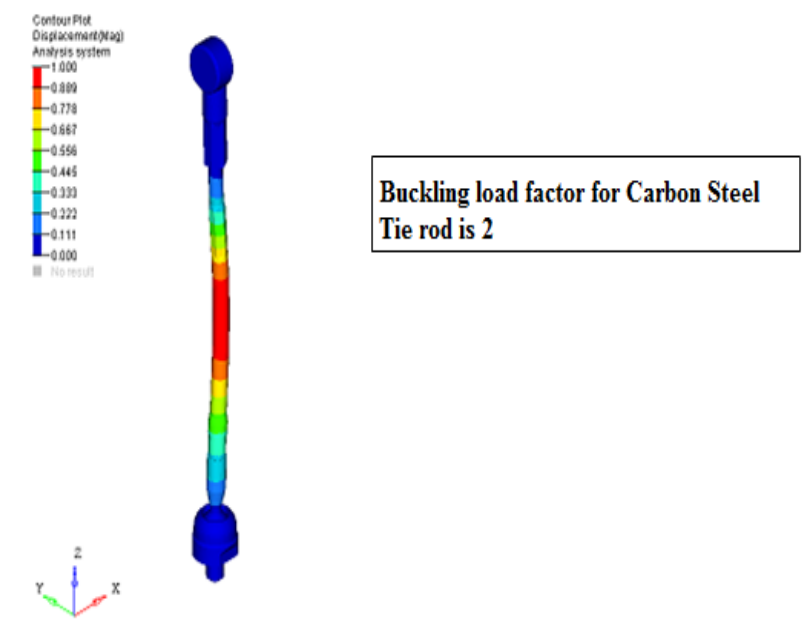

Fig -19: Buckling Mode Shape for Carbon Steel Tie Rod

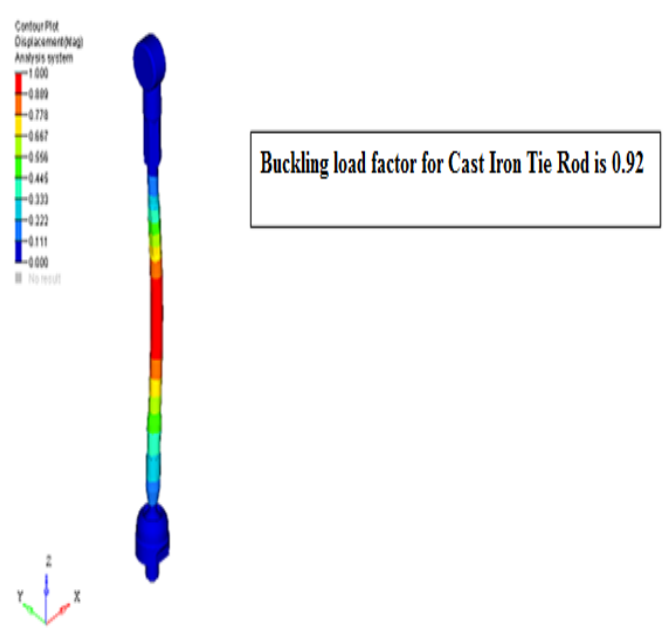

Fig -20: Buckling Mode Shape for Cast Iron Tie Rod

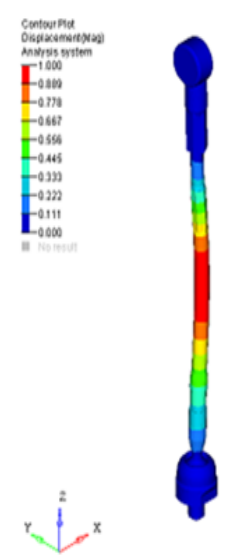

Buckling load factor for Aluminium Alloy Tie rod is 0.64

Fig -21: Buckling Mode Shape for Aluminium Alloy Tie Rod

\subsection{Max. /Critical Buckling Load $P_{\text {cr }}$ for Tie Rod using FE Results}

Max. /Critical buckling load $\mathrm{P}_{\mathrm{cr}}$ for Tie rod calculation using FE results is carried out by taking $18.68 \mathrm{KN}$ force and load factor 2 for carbon steel Tie rod, 0.92 for cast iron Tie rod and 0.64 for aluminium alloy Tie rod.

Therefore, the Max. /Critical Buckling load for Tie rod is given by

$$
\mathrm{P}_{\mathrm{cr}}=\text { Load factor } \times \text { Applied load }
$$

The critical buckling load obtained for carbon steel Tie rod is $37.36 \mathrm{KN} / \mathrm{mm}$, for cast iron Tie rod is $17.18 \mathrm{KN} / \mathrm{mm}$ and for aluminium alloy Tie rod is $11.95 \mathrm{KN} / \mathrm{mm}$.

\section{THEORETICAL CALCULATIONS}

\subsection{Calculations to find Deflection of Tie Rod}

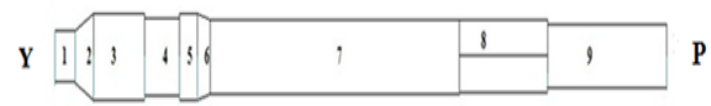

Fig -22: Portion of the Tie Rod 
Let $1,2,3,4,5 \ldots$. are the portions of Tie rod whose respective lengths are $\mathrm{L}_{1}, \mathrm{~L}_{2}, \mathrm{~L}_{3}, \mathrm{~L}_{4}, \mathrm{~L}_{5}, \mathrm{~L}_{6}, \mathrm{~L}_{7}, \ldots$ and respective cross sectional area of the portions be $A_{1}, A_{2}, A_{3}$, $\mathrm{A}_{4}, \mathrm{~A}_{5} \ldots$ and $\mathrm{E}$ be the Young's modulus of the material and $\mathrm{P}$ be the applied axial load and $\mathrm{Y}$ is constrained in all DOF [11].

Where,
$\mathrm{L}_{1}=9 \mathrm{~mm}$
$\mathrm{L}_{2}=9 \mathrm{~mm}$
$\mathrm{L}_{3}=23 \mathrm{~mm}$
$\mathrm{L}_{4}=16 \mathrm{~mm}$
$\mathrm{L}_{5}=8 \mathrm{~mm}$
$\mathrm{L}_{6}=6 \mathrm{~mm}$
$\mathrm{L}_{7}=113 \mathrm{~mm}$
$\mathrm{L}_{8}=12 \mathrm{~mm}$
$\mathrm{L}_{9}=54 \mathrm{~mm}$
$\mathrm{D}_{1}=9.35 \mathrm{~mm}$
$\mathrm{D}_{3}=15.5 \mathrm{~mm}$
$\mathrm{D}_{4}=14 \mathrm{~mm}$
$\mathrm{D}_{5}=15.5 \mathrm{~mm}$
$\mathrm{D}_{7}=13.3 \mathrm{~mm}$
$\mathrm{D}_{9}=11.5 \mathrm{~mm}$

Change in Length of Tie Rod

$$
\begin{gathered}
\delta_{L}=\delta_{1}+\delta_{2}+\delta_{3}+\delta_{4}+\delta_{5} \cdots \cdots \cdots \\
\delta L=\frac{P L_{1}}{A_{1} E}+\frac{P L_{2}}{A_{2} E}+\frac{P L_{3}}{A_{3} E}+\frac{P L_{4}}{A_{4} E}+\frac{P L_{5}}{A_{5} E} \cdots \cdots
\end{gathered}
$$

Using this formula the deflection of the Tie rod is $0.171 \mathrm{~mm}$ for carbon steel Tie rod, $0.303 \mathrm{~mm}$ for cast iron Tie rod, and $0.520 \mathrm{~mm}$ for aluminium alloy Tie rod.

\subsection{Stiffness Calculation for Tie Rod using}

\section{Theoretical Results}

Stiffness calculation for Tie rod using theoretical results is carried out by taking $18.68 \mathrm{KN}$ load and $0.171 \mathrm{~mm}$ deflection for carbon steel Tie rod, $0.303 \mathrm{~mm}$ deflection for cast iron Tie rod and $0.520 \mathrm{~mm}$ deflection for aluminium alloy Tie rod.

Therefore, Stiffness (K) is given by

$$
K=\frac{\text { LOAD }}{\text { DEFLECTION }}
$$

Using the above formula Stiffness obtained for carbon steel Tie rod is $109 \mathrm{KN} / \mathrm{mm}$, cast iron Tie rod is $61.65 \mathrm{KN} / \mathrm{mm}$ and aluminium alloy Tie rod is $35.92 \mathrm{KN} / \mathrm{mm}$.

\subsection{Calculations to find Critical Buckling Load for}

\section{Tie Rod}

The Euler's buckling formula for column one end fixed and other end hinged is given by,

$$
\mathrm{P}_{\mathrm{cr}}=\frac{2 \times \pi^{2} \times \mathrm{E} \times \mathrm{I}}{\mathrm{l}^{2}}
$$

Where,

$\mathrm{P}_{\text {cr }}=$ Critical/Max. Load in $\mathrm{N}$.

$\mathrm{E}=$ Modulus of Elasticity in $\mathrm{N} / \mathrm{mm}^{2}$.

$\mathrm{I}=$ Moment of Inertia in $\mathrm{mm}^{4}$.

$\mathrm{L}=$ Actual length in $\mathrm{mm}$.
Using this formula the critical buckling load for Tie rod is 42.29 KN. 24.16 KN, 14.09 KN for carbon steel Tie rod, cast iron Tie rod, and aluminium alloy Tie rod respectively.

\section{RESULTS AND DISCUSSIONS}

\subsection{Static Analysis}

\section{- $\quad$ FE Displacement Results for Tie Rod}

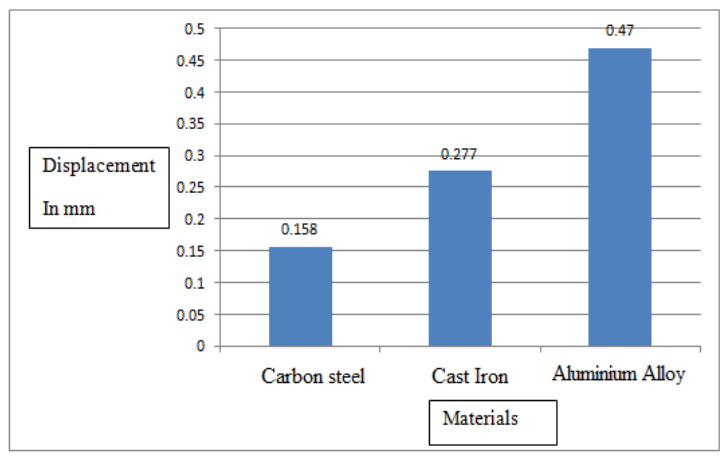

Fig -23: FE Displacement Results for Tie Rod

\section{- Theoretical Displacement Results for Tie Rod}

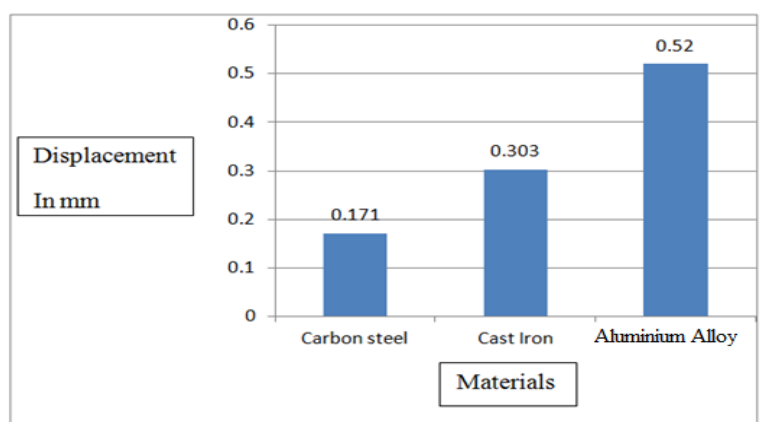

Fig -24: Theoretical Displacements Results for Tie Rod

From the figure $22 \mathrm{FE}$ displacement results for carbon steel Tie rod is $0.158 \mathrm{~mm}$, cast Iron Tie rod is $0.277 \mathrm{~mm}$ and aluminium alloy Tie rod is $0.47 \mathrm{~mm}$. and from the figure 23 theoretical displacement results for carbon steel Tie rod is $0.171 \mathrm{~mm}$, cast Iron Tie rod is $0.303 \mathrm{~mm}$ and aluminium alloy Tie rod is $0.520 \mathrm{~mm}$. Among the carbon steel Tie rod is having least displacement. Hence carbon steel Tie rod is safe for design of car Tie rod.

\section{- $\quad$ Stress Results}

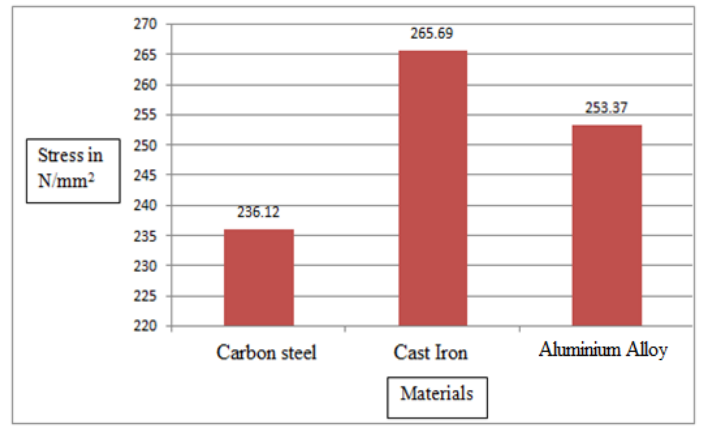

Fig -25: Stress Results for Tie Rod 
From the above stress chart the stress for carbon steel Tie $\operatorname{rod}$ is $236.12 \mathrm{~N} / \mathrm{mm}^{2}$, cast Iron Tie rod is $265.69 \mathrm{~N} / \mathrm{mm}^{2}$ and aluminium alloy Tie rod is $253.37 \mathrm{~N} / \mathrm{mm}^{2}$. The standard yield strength of the carbon steel is $320 \mathrm{~N} / \mathrm{mm}^{2}$ and the analytical yield strength of carbon steel is $236.12 \mathrm{~N} / \mathrm{mm}^{2}$, which is less than the value of standard yield strength. So carbon steel Tie rod is safe for design of car Tie rod.

\subsubsection{Stiffness Calculation Results for Tie Rod}

The stiffness calculation results for Tie rod obtained are shown in the table 3 .

Table -3: Stiffness Results of Tie Rod for Different Materials

\begin{tabular}{|c|c|c|c|}
\hline Materials & $\begin{array}{l}\text { Carbon } \\
\text { Steel Tie } \\
\text { Rod }\end{array}$ & $\begin{array}{l}\text { Cast } \\
\text { Iron Tie } \\
\text { Rod }\end{array}$ & $\begin{array}{l}\text { Aluminium } \\
\text { Alloy Tie } \\
\text { Rod }\end{array}$ \\
\hline $\begin{array}{l}\mathrm{K} \text { in }(\mathrm{KN} / \mathrm{mm}) \\
\text { using FE Results }\end{array}$ & 118.22 & 67.43 & 39.74 \\
\hline $\begin{array}{lr}\text { in in } & (\mathrm{KN} / \mathrm{mm}) \\
\text { using } & \text { Theoretical } \\
\text { Results } & \end{array}$ & 109 & 61 & 35 \\
\hline
\end{tabular}

\subsubsection{Stiffness Calculation for Carbon Steel Tie Rod}

The calculated stiffness results for carbon steel Tie rod is given in the below table 4 .

Table -4: Stiffness Results for Carbon Steel Tie Rod

\begin{tabular}{|l|l|l|l|}
\hline Analysis & Experimental & Theoretical & FEA \\
\hline $\begin{array}{l}\text { Stiffness in } \\
\text { KN/mm }\end{array}$ & 103.77 & 109.23 & 118.2 \\
\hline
\end{tabular}

It has been found by the above table 4 the Stiffness results for car Tie Rod meets the experimental and FEA results by $12.20 \%$ error.

\subsection{Normal Modal Analysis}

\section{- Natural Frequency and Mode Shapes Results}

Table -5: Mode Shapes at Different Natural Frequency for Different Materials

\begin{tabular}{|l|l|l|l|l|}
\hline $\begin{array}{l}\text { Sl. } \\
\text { No. }\end{array}$ & $\begin{array}{l}\text { Mode } \\
\text { Shapes }\end{array}$ & $\begin{array}{l}\text { Natural } \\
\text { Frequency } \\
\text { of Carbon } \\
\text { Steel Tie } \\
\text { Rod } \\
\mathrm{Hz}\end{array}$ & $\begin{array}{l}\text { Natural } \\
\text { Frequency } \\
\text { of Cast } \\
\text { Iron Tie } \\
\text { Rod } \\
\mathrm{Hz}\end{array}$ & $\begin{array}{l}\text { Natural } \\
\text { Frequency } \\
\text { of } \\
\text { Aluminium } \\
\text { Alloy Tie } \\
\text { Rod } \\
\mathrm{Hz}\end{array}$ \\
\hline 1 & $\begin{array}{l}1^{\text {st }} \\
\text { Mode }\end{array}$ & 833 & 652.4 & 829.8 \\
\hline 2 & $\begin{array}{l}2^{\text {nd }} \\
\text { Mode }\end{array}$ & 844.7 & 661.7 & 841.1 \\
\hline 3 & $\begin{array}{l}3^{\text {rd }} \\
\text { Mode }\end{array}$ & 1961 & 1538 & 1944.1 \\
\hline 4 & $\begin{array}{l}4^{\text {th }} \\
\text { Mode }\end{array}$ & 2014 & 1580 & 1995 \\
\hline
\end{tabular}

\begin{tabular}{|l|l|l|l|l|}
\hline 5 & $\begin{array}{l}5^{\text {th }} \\
\text { Mode }\end{array}$ & 3524 & 2767 & 3485 \\
\hline
\end{tabular}

From the above table 5 the natural frequencies of carbon steel, cast Iron and aluminium alloy Tie rod ae compared. For $1^{\text {st }}$ Mode carbon steel Tie rod is having $833 \mathrm{~Hz}$ natural frequency. For $1^{\text {st }}$ Mode cast iron Tie rod is having 652.4 Hz. And. For $1^{\text {st }}$ Mode aluminium alloy Tie rod is having $829.8 \mathrm{~Hz}$. The carbon steel Tie rod is having higher natural frequency than cast iron and aluminium alloy Tie rod. So carbon steel Tie rod is stiffer than cast Iron and aluminum alloy Tie rod. Hence carbon steel Tie rod is safe for designing the car Tie rod.

\subsection{Buckling Analysis Results for Tie Rod}

Table -6: Critical Buckling Load Results for Tie Rod

\begin{tabular}{|l|l|l|l|}
\hline $\begin{array}{l}\text { Critical } \\
\text { Buckling } \\
\text { Load }\end{array}$ & $\begin{array}{l}\text { Carbon } \\
\text { Steel Tie } \\
\text { Rod }\end{array}$ & $\begin{array}{l}\text { Cast } \\
\text { Iron Tie } \\
\text { Rod }\end{array}$ & $\begin{array}{l}\text { Aluminium } \\
\text { Alloy Tie } \\
\text { Rod }\end{array}$ \\
\hline $\begin{array}{l}\mathrm{P}_{\text {cr } \text { in KN }} \text { Using } \\
\text { Results }\end{array}$ & 37.36 & 17.18 & 11.95 \\
\hline $\begin{array}{l}\mathrm{P}_{\text {cr }} \text { in KN } \\
\text { Using } \\
\text { Theoretical } \\
\text { Results }\end{array}$ & 42.29 & 24.16 & 14.09 \\
\hline
\end{tabular}

The Max.Buckling load for Tie rod using FE results and theoretical results is shown in the table 6. Among carbon steel Tie rod is giving good results compared to cast iron and aluminium alloy Tie rod. Hence carbon steel Tie rod is preferable material for the design of car Tie rod.

\subsubsection{Buckling Analysis Results for Carbon Steel}

\section{Tie Rod}

The critical buckling load results for carbon steel Tie rod are given in the table 7 .

Table -7: Critical Buckling Load Results for Carbon Steel Tie Rod

\begin{tabular}{|l|l|l|}
\hline Analysis & $\begin{array}{l}\text { Theoretical } \\
\text { Analysis }\end{array}$ & FE Analysis \\
\hline $\begin{array}{l}\text { Critical Buckling } \\
\text { load } \\
\mathrm{P}_{\text {cr } \text { in KN }}\end{array}$ & 42.29 & 37.36 \\
\hline
\end{tabular}

It has been found by the above table 7 the critical buckling load results for car Tie rod meets the theoretical analysis and FE analysis results by $11.65 \%$ error.

\section{CONCLUSION AND SCOPE OF FUTURE WORK}

\subsection{Conclusions}

- $\quad$ Meshed model of Tie rod satisfied all quality criteria and hence the FEA results are accurate. 
- In this project, the experimental stiffness value of the purchased tie rod made out of carbon steel is 103.77 KN/mm which meets closely with the theoretical stiffness value $109.23 \mathrm{KN} / \mathrm{mm}$ and stiffness value is $118.22 \mathrm{KN} / \mathrm{mm}$ obtained using FEA.

- The error between the experimental and FEA stiffness is $12.20 \%$, which is acceptable error. It should be noted that the elements which are $1^{\text {st }}$ order TET4 elements and in experiment actual tie rod is used, the material defects if any are there is taken care during the experimentation, so this can lead to the errors.

- The natural frequency and mode shapes of Tie rod are obtained by normal model analysis. The $1^{\text {st }}$ Mode natural frequency of carbon steel Tie rod is $833 \mathrm{~Hz}$, cast iron Tie rod is $652.4 \mathrm{~Hz}$ and aluminium alloy Tie rod is $829.8 \mathrm{~Hz}$.

- $\quad$ The $1^{\text {st }}$ Mode natural frequency of carbon steel Tie rod component is greater than the cast iron and aluminium Tie rod component, so carbon steel Tie rod is more suitable material for design of car Tie rod.

- The theoretical calculated critical buckling load for carbon steel Tie rod is $42.29 \mathrm{KN}$ closely meets with the FEA critical buckling load for carbon steel Tie rod is $37.36 \mathrm{KN}$.

- The error between the experimental and FEA critical buckling load is $11.65 \%$, which is acceptable error. It should be noted that the elements which are $1^{\text {st }}$ order TET4 elements and in experiment actual tie rod is used, the material defects if any are there is taken care during the experimentation, so this can lead to the errors.

- $\quad$ Carbon steel material is suitable for the manufacture of the Tie rod of an automobile vehicle as it shows better mechanical properties compared to cast iron and aluminum alloy material.

\subsection{Scope of Future Work}

- Similar analysis approach can be followed for any type of Tie rod, in general for heavy and light vehicle.

- Dynamic analysis can be carried out for the Impact loading and random changes of the load on Tie Rod due to uneven road.

- Fatigue life estimation of each component can be performed for car Tie Rod.

- Non linear analysis cab be carried out for Tie rod component.

\section{REFERENCES}

[1] Anthony DeLugan "Predicting the Buckling Load of a Structural Tie Rod due to Axial Compression", Thesis Report Submitted to Rensselaer Polytechnic Institute, Hartford, CT May 2012.

[2] Manik A Patil, "FEA of Tie Rod Steering System of Car", International Journal of Application or
Innovation Engineering and Management, volume 2, issue 5, May2013, ISSN 2319-4847.

[3] Wei Duan a, Suraj Joshi, "Failure Analysis of Threaded Connections in Large-Scale Steel Tie Rods", Engineering Failure Analysis, Volume 18, Issue 8, December 2011, Pages 2008-2018.

[4] A.H. Falah , M.A. Alfares, A.H. Elkholy, "Failure Investigation of a Tie Rod End of an Automobile Steering System", Journal of Engineering Failure Analysis, Volume 14, Issue 5, July 2007, Pages 895902.

[5] Nitin S Gokhale, Practicle Finite Element Analysis, Finite to Infinite Publishers, Publication 2008.

[6] Gongeng Jiang, YiLiang Zhang, XueDong Xu, DaWei Ding, "Stability and Failure Analysis of Steering Tie Rod", Proceedings of SPIE 7375, International Conference on Experimental Mechanics 2008, Article Id 73753A (August 25, 2009), doi:10.1117/12.839249.

[7] Sergio Lagomarsino, Chiara Calderini, "The Dynamical Identification of the Tensile Force in Ancient Tie Rods", Engineering Structures 01/2005, 27(6), 846-856, DOI: 10.1016/j.engstructJan.2005.

[8] Dobrivoje Catic, "Criticality Analysis of the Elements of the Light Commercial Vehicle Steering Tie Rod Joint", Strojniški vestnik, Journal of Mechanical Engineering , 57(2011)6, 495-502, DOI:10.5545/sv-jme.2010.077, 2011.

[9] George Campbell and Wen Ting, "Buckling and Geometric Nonlinear Analysis of a Tie Rod in NASTRAN VERSION68", 22nd MSC World Users Conference Paper AIAA 94-1671, Apr 21-22, 1994.

[10] J. K. KIM "Structural design of an Outer Tie rod for a Passenger car", International Journal of Automotive Technology, Vol. 12, No. 3, pp. 375-381 (2011); DOI $10.1007 / \mathrm{s} 12239-011-0044-6$.

[11] S. S. Bhavikatti, "Strength of Materials", Vikas Publishing House Pvt Ltd, Second Revised edition 2003 